\title{
Accuracy of ultrasound scan guided needle biopsy in pre- operative diagnosis of metastatic axillary lymphadenopathy in patients with breast cancer
}

\author{
Mohsen M. El Gammal ${ }^{1 *}$, Chin Ng² ${ }^{2}$ Amrita Kumar ${ }^{2}$, Margaret Moorland², Razan Gardy ${ }^{3}$ and Richard Sainsbury ${ }^{1}$ \\ *Correspondence: Mohsen.elgammal@fhft.nhs.uk \\ 'Department of Breast Surgery, Parapet Breast Centre, Frimley Health Foundation Trust -King Edwards VII Hospital, Windsor, \\ SL4 3DP, United Kingdom. \\ 2Department of Radiology, Parapet Breast Centre, Frimley Health Foundation Trust, King Edwards VII Hospital, Windsor, SL4 3DP, \\ United Kingdom. \\ ${ }^{3}$ Department of Histopathology, Wexham and Heatherwood Hospital, Frimley Health Foundation Trust, slough, SL2 4DP, \\ United Kingdom.
}

\begin{abstract}
Background: Pre-operative diagnosis of axillary node status is important in the management of patients with breast cancer. Ultrasound scanning (US) is an essential part of triple assessment of these patients with biopsy by either fine needle aspiration cytology (FNAC) and/or core biopsy (CB) of suspicious lymph nodes. The aim of this study is to establish the accuracy of preoperative US scan with US guided needle biopsy (USB) of suspicious nodes in the diagnosis of metastatic disease. Compliance with the current recommendations of the Royal College of Radiologists (RCR) was audited.

Material and methods: A retrospective analysis of all patients diagnosed with invasive breast cancer from April 2015 till March 2016 who underwent preoperative US axillary assessment followed by axillary surgery. Preoperative ultrasounds and US guided FNAC or CB of axillary lymph nodes were correlated with final histology of sentinel lymph node biopsy (SLN) or axillary lymph node clearance (ALND). Patients with micro-metastasis were excluded from this analysis.

Findings or results: 292 patients were identified (163 symptomatic invasive breast cancers and 129 screen detected). Following axillary surgery $95 / 292(32.5 \%)$ patients had nodal metastatic involvement on final histology. 68/163 (41.7\%) of the symptomatic group had proven metastatic disease on final histology whereas only $27 / 129$ (20.9\%) of the screen detected group had metastatic disease. The sensitivity of US alone diagnosis in the symptomatic group was $73.5 \%$ and US guided sampling was $76 \%$ whereas in the screening group the sensitivity of ultrasound was $44.4 \%$ and ultrasound biopsy $83 \%$ respectively.

Conclusions: Our results better the Royal College of Radiology guidelines (target of 50\% or above) for both US assessment and US guided biopsy for symptomatic group. The screening group results were lower than the symptomatic group which probably is a reflection of a lower metastatic burden.
\end{abstract}

Keywords: Breast cancer, axillary lymph nodes, ultrasound scan, metastases, needle biopsy

\section{Introduction}

Ultrasound of the axilla should be performed in all patients when breast malignancy is suspected [1]. Lymph nodes showing abnormal morphology on ultrasound should undergo ultrasound guided needle biopsy-sampling (USB). Lymph node biopsy may be performed using FNAC or CB [1]. The addition of US -FNAC in cases of suspicious for malignancy may prevent more than $50 \%$ of sentinel lymphadenectomies, significantly shortening the time interval to definitive surgery [2].

There is no agreed standard for accuracy [3]. Several groups have published their results [4-8] with a reported sensitivity for detection of metastatic axillary lymph nodes ranging from $54.1 \%$ to $68.2 \%$ and the sensitivity of ultrasound guided FNAC/ biopsy ranging from $28.5 \%$ to $55.6 \%$. A positive correlation 
has been reported between the preoperative USB diagnosis of metastatic disease and the underlying prevalence of ALN metastases [9]. Further studies have also confirmed that the sensitivity of US and USB depends on the extent of axillary tumor burden [10-12]. Meta-analysis studies have reported that preoperative USB of the axilla is accurate for initial staging of women with invasive breast cancer [9] and is a useful step in the process of axillary staging [13]. Approximately $50 \%$ of women with axillary involvement can be identified preoperatively [13].

The aim of this single centre retrospective study was to evaluate our results against the standards defined by the RCR (greater than $50 \%$ sensitivity). This sensitivity should be equal to prevalence of axillary nodal metastatic disease in first time presenters to the local symptomatic breast service [3].

\section{Findings or results}

A total of 292 patients were identified (163 symptomatic invasive breast cancers and 129 screen detected). All patients underwent US of their ipsilateral axilla. USB of Suspicious lymph nodes was performed with the following morphological criteria: cortical thickness of $\geq 2.5 \mathrm{~mm}$, focal cortical bulge, complete or partial effacement of the fatty hilum, complete or partial replacement of the node with irregular or ill-defined mass, microcalcification in a node and hypoechoic node round.

After axillary surgery 95/292 (32.5\%) patients had nodal metastatic involvement on final histology. $68 / 163$ of the symptomatic group (41.7\%) but only $27 / 129$ (20.9\%) of the screen detected group had proven metastatic disease on final histology (Table 1). The sensitivity of US diagnosis of symptomatic patients was $73.5 \%$ and US guided sampling of $76 \%$ compared to the screen group of $44.4 \%$ and $83 \%$ respectively.

The choice of method of axillary biopsy (cytology or core) depends on the individual radiologist and their training. False negatives occurred equally ( 6 and 6 for symptomatic $24 \%$ and 1 and 1 for screen detected disease 20\%) for both techniques

Table 1. Symptomatic versus Screen detected USB \& False Negative Results.

\begin{tabular}{lllll}
\hline \multicolumn{5}{c}{ Total 292 patients } \\
\hline & Symptomatic=163 & Screening=129 \\
\hline $\begin{array}{l}\text { Positive } \\
\text { nodes } \\
\text { at surgery }\end{array}$ & 68 & & 27 \\
\hline $\begin{array}{l}\text { Pre-op US } \\
\text { appearance }\end{array}$ & NORMAL & ABNORMAL & NORMAL & ABNORMAL \\
\hline USB & -- & 50 & $\mathbf{1 5}$ & $\mathbf{1 2}$ \\
POSTIVE & & Core 10, & -- & 10 \\
& & FNAC 28 & & Core 3, \\
USB & & 12 & & FNAC 7 \\
negative & --- & Core 6, & -- & Core 1, \\
& & FNAC 6 & & FNAC 1 \\
False & $18 / 68$ & $12 / 50$ & $15 / 27$ & $2 / 10$ \\
negative & $26 \%$ & $24 \%$ & $55 \%$ & $20 \%$ \\
\hline
\end{tabular}

(Table 1). Positive predictive value of USB was $100 \%$ and $0 \%$ false positive USB.

$48 / 95$ (50\%) of patients with metastatic lymph nodes underwent direct definitive axillary clearance following their pre-operative diagnosis on USB.47 of the 292 patients (16\%) had to undergo a second surgical axillary procedure as their nodal positivity was not diagnosed on preoperative imaging(normal US or negative USB does preclude lymph node involvement). This figure may reduce in the future as trials such as PosNoc report [14].

\section{Conclusions}

Our results meet the Royal College of Radiology guidelines (targets of $50 \%$ or above) for both US assessment and US guided biopsy for symptomatic group. The screening group results were lower than the symptomatic group possibly due to smaller size and earlier stage of the tumours(lower prevalence rate). $50 \%$ of patients with metastatic nodes could be spared unnecessary SLN and proceed to definitive axillary treatment following positive USB. Better methods of detection of axillary nodal metastases, especially in the screening group, should be investigated.

\section{Competing interests}

The authors declare that they have no competing interests.

Authors' contributions

\begin{tabular}{|l|c|c|c|c|c|c|}
\hline Authors' contributions & ELG & CNG & AK & MM & RG & RS \\
\hline Research concept and design & $\checkmark$ & $\checkmark$ & $\checkmark$ & $\checkmark$ & -- & -- \\
\hline Collection and/or assembly of data & -- & $\checkmark$ & -- & -- & $\checkmark$ & -- \\
\hline Data analysis and interpretation & $\checkmark$ & $\checkmark$ & $\checkmark$ & -- & -- & $\checkmark$ \\
\hline Writing the article & $\checkmark$ & -- & -- & -- & -- & $\checkmark$ \\
\hline Critical revision of the article & $\checkmark$ & $\checkmark$ & -- & -- & -- & $\checkmark$ \\
\hline Final approval of article & $\checkmark$ & $\checkmark$ & -- & -- & -- & $\checkmark$ \\
\hline Statistical analysis & $\checkmark$ & $\checkmark$ & -- & -- & -- & $\checkmark$ \\
\hline
\end{tabular}

\section{Acknowledgement}

This study has been presented as a poster abstract at the European Cancer Conference 2017 On the $28^{\text {th }}$ of January, Amsterdam, the Netherlands.

\section{Publication history}

Editor: Subhasis Misra, Texas Tech University, USA.

Received: 09-Jan-2017 Final Revised: 22-Feb-2017

Accepted: 28-Feb-2017 Published: 07-Mar-2017

\section{References}

1. Alexis M Willett, Michael J Michell, Martin J R Lee. Best practice diagnostic guidelines for patients presenting with breast symptoms. best practice guidelines - Association of Breast Surgery. November 2010. I Pdf

2. Rocha RD, Girardi AR, Pinto RR and de Freitas VA. Axillary ultrasound and fine-needle aspiration in preoperative staging of axillary lymph nodes in patients with invasive breast cancer. Radiol Bras. 2015; 48:345-52. | Article | PubMed Abstract | PubMed FullText

3. Senthil K A Ragupathy. Axillary ultrasound accuracy in the symptomatic breast service. TheRoyal College of Radiologists. August 2010 and updated 2014. I Website 
El Gammal et al., Breast Cancer Reports 2017,

http://www.hoajonline.com/journals/pdf/2057-1631-4-1.pdf

4. Baruah BP, Goyal A, Young P, Douglas-Jones AG and Mansel RE. Axillary node staging by ultrasonography and fine-needle aspiration cytology in patients with breast cancer. Br J Surg. 2010; 97:680-3. | Article | PubMed

5. Damera A, Evans AJ, Cornford EJ, Wilson AR, Burrell HC, James JJ, Pinder $\mathrm{SE}$, Ellis IO, Lee AH and Macmillan RD. Diagnosis of axillary nodal metastases by ultrasound-guided core biopsy in primary operable breast cancer. Br J Cancer. 2003; 89:1310-3.| Article | PubMed Abstract I PubMed Full Text

6. Jung J, Park H, Park J and Kim H. Accuracy of preoperative ultrasound and ultrasound-guided fine needle aspiration cytology for axillary staging in breast cancer. ANZ J Surg. 2010; 80:271-5. | Article I PubMed

7. Sapino A, Cassoni P, Zanon E, Fraire F, Croce S, Coluccia C, Donadio M and Bussolati G. Ultrasonographically-guided fine-needle aspiration of axillary lymph nodes: role in breast cancer management. $\mathrm{Br} J$ Cancer. 2003; 88:702-6. | Article | PubMed Abstract | PubMed Full Text

8. Susini T, Nori J, Olivieri S, Molino C, Marini G, Bianchi S, Vezzosi V, Livi L, Mascalchi M and Scarselli G. Predicting the status of axillary lymph nodes in breast cancer: a multiparameter approach including axillary ultrasound scanning. Breast. 2009; 18:103-8. | Article | PubMed

9. Houssami N, Ciatto S, Turner RM, Cody HS, 3rd and Macaskill P. Preoperative ultrasound-guided needle biopsy of axillary nodes in invasive breast cancer: meta-analysis of its accuracy and utility in staging the axilla. Ann Surg. 2011; 254:243-51. I Article I PubMed

10. Stachs A, Gode K, Hartmann S, Stengel B, Nierling U, Dieterich M, Reimer $\mathrm{T}$ and Gerber B. Accuracy of axillary ultrasound in preoperative nodal staging of breast cancer - size of metastases as limiting factor. Springerplus. 2013; 2:350. | Article | PubMed Abstract | PubMed Full Text

11. Lee B, Lim AK, Krell J, Satchithananda K, Coombes RC, Lewis JS and Stebbing J. The efficacy of axillary ultrasound in the detection of nodal metastasis in breast cancer. AJR Am J Roentgenol. 2013; 200:W314-20. I Article I PubMed

12. Moorman AM, Bourez RL, Heijmans HJ and Kouwenhoven EA. Axillary ultrasonography in breast cancer patients helps in identifying patients preoperatively with limited disease of the axilla. Ann Surg Oncol. 2014; 21:2904-10. | Article | PubMed

13. Diepstraten SC, Sever AR, Buckens CF, Veldhuis WB, van Dalen T, van den Bosch MA, Mali WP and Verkooijen HM. Value of preoperative ultrasound-guided axillary lymph node biopsy for preventing completion axillary lymph node dissection in breast cancer: a systematic review and meta-analysis. Ann Surg Oncol. 2014; 21:51-9. I Article I PubMed

14. Positive sentinel node: adjuvant therapy alone versus adjuvant therapy plus clearance or axillary radiotherapy. POSNOC Trial. | Website

\section{Citation:}

El Gammal MM, Ng C, Kumar A, Moorland M, Gardy R and Sainsbury R. Accuracy of ultrasound scan guided needle biopsy in preoperative diagnosis of metastatic axillary lymphadenopathy in patients with breast cancer. Breast Cancer Rep. 2017; 4:1.

http://dx.doi.org/10.7243/2057-1631-4-1 